\title{
A Study on Health Recognition of Local Residents to Establish Local Healthcare Projects in the with-COVID-19 Age
}

\author{
Bo-Woo Lee
}

Department of Radiological Science, Gimcheon University, Daehakro 214 Gimcheon City, Korea; moobbo@hanmail.net; Tel.: +82-10-2006-7168

\begin{abstract}
Objectives: This study aimed to analyze the awareness of local residents regarding healthcare projects and to suggest some ideas for the revision of local ones. Methods: To delve into the opinions of local residents, the author of this study created a questionnaire composed of eight questions on the general characteristics of the respondents, eight questions on satisfaction with health centers, 16 questions on the awareness of healthcare projects, and 22 questions on local healthcare. The survey was conducted for 409 residents who visited public centers in Gimcheon from 15 March to 14 April 2021. Results: Data analysis revealed the following: The proportion of local residents who use health centers was $39.1 \%$, and those users visit health centers, on average, 3.92 times a year. Among healthcare projects, the project known by the highest proportion of people was vaccinations $(84.5 \%)$, which was also the project that was most used $(38.1 \%)$. Among healthcare projects needed in the with-COVID-19 age, respondents awarded the highest score to vaccinations (4.15 points on a five-point Likert scale) and the second highest score to infectious disease management (4.12). Conclusions: For healthcare projects, central and local governments should focus on activating vaccinations, solving the problem of medical accessibility through untact remote treatment and establishing national infectious disease-specializing hospitals and local infectious disease management based on such national hospitals.
\end{abstract}

Keywords: COVID-19; with- COVID-19 age; infectious disease; local healthcare projects; healthcare systems

\section{Introduction}

COVID-19 has spread throughout the world, and it has not disappeared like other corona-based viruses, such as SARS (severe acute respiratory syndrome) and MERS (Middle East respiratory syndrome), have [1,2]. America and European countries have made efforts to form herd immunity by raising their vaccine immunization ratios. However, with increases in the breakthrough infections of those who are vaccinated by coronavirus variants, the herd immunity of a whole population becomes hard to achieve [3-6]. Consequently, we need to prepare for a "with-COVID-19 age" rather than expecting the end of COVID-19.

To prevent the spread of COVID-19, we urgently need to take quarantine measures and revise healthcare systems $[7,8]$, which can vary depending on the historical, economic, and cultural characteristics of different regions [8,9]. The Korean healthcare system has been highly praised in the way it is dealing with the COVID-19 crisis [10,11]. However, given that Korea has been rather slow to vaccinate its population, we need to reexamine its healthcare system. Additionally, each region should have its own specifically suitable healthcare system.

The role of health centers is important in establishing a regional healthcare system. A health center should establish plans regarding its healthcare system, upgrade the quality of its healthcare service, and promote health improvements of local residents [12-14]. Article 3 of the Regional Health Law stipulates that the head of local govern- 
ment should establish the local healthcare plan and submit it to the Minister of Health and Welfare $[15,16]$. Through this, the local government contributes to the local community and the health of local residents.

Up to now, the most important issue in local healthcare systems has been the management of the chronic diseases of old people that have arrived alongside the rapid increase in old residents [17-19]. However, local healthcare systems in the "with-corona" era should focus on the prevention of infective diseases rather than on the management of chronic diseases. However, local health centers with limited personnel and budgets have difficulties in solving local healthcare issues [20,21]. Accordingly, when establishing a local healthcare system, it is not enough for workers in health centers to promote health projects. It is necessary to collect the opinions of local residents and allow them to participate in the establishment of healthcare plans, as well as become aware of what the healthcare system is. It is also desirable to allow local residents to participate in and lead healthcare projects.

The author of this study aimed to examine various opinions regarding local healthcare by conducting a survey of the local residents of a city. Additionally, based on the findings of the survey, especially regarding local resident needs in the with-COVID-19 era, we intended to suggest directions to improve healthcare services.

\section{Methodology}

\subsection{Research Design}

This study was based on descriptive empirical research. We surveyed local residents regarding local healthcare systems, and, based on the survey findings, intended to suggest ways to improve local healthcare systems.

\subsection{Survey Objects}

The author of this study conducted a survey of visitors to health center branches in Gimcheon, Gyeongbook Province. Copies of the questionnaire were distributed to 435 people, and after the exclusion of 26 copies that had problems, 409 copies were used in the final analysis. The respondents were provided the intention of the survey and asked to fill it out by themselves.

\subsection{Data Collection}

The survey was conducted via the following procedure. First, the researcher received approval for the survey from the directors of the visited health centers and branches. The survey was conducted from 15 March to 14 April 2021. The respondents were informed that they could voluntarily participate in the survey, they could stop answering the questions at any time, and there would be no penalties for any of their answers.

\subsection{Research Tools}

As there was no tool to measure satisfaction with the use of health centers and the perception of healthcare projects, the researcher created a questionnaire by consulting professional workers in healthcare, referring to the work guidelines and plans of health centers, and reviewing the related literature. To improve the validity of the questionnaire, the author of this study consulted three professional workers in local healthcare and two professors in nursing science.

The research tool of this study was the questionnaire, which consisted of 55 questions: Nine questions on the general characteristics of respondents, eight questions on satisfaction with the use of health centers, 16 questions on the awareness of health projects, and 22 questions on the awareness of local healthcare systems. Except for the questions on general characteristics, the respondents were asked to indicate their opinions via a five-point Likert scale. The Cronbach's $\alpha$ values were as follows: 0.963 for satisfac- 
tion with the use of health centers, 0.950 for the awareness of health projects, and 0.931 for the awareness of local healthcare systems.

\subsection{Analytical Method}

To analyze the data, the author of this study used the SPSS WIN 23.0 program (IBM Co., Armonk, NY, USA). Frequency analysis was conducted to examine the general characteristics of the respondents. The reliability of the research tools was measured with Cronbach's $\alpha$. To measure satisfaction with the use of health centers, chi-square tests and $t$-tests were applied. The awareness of health projects and the awareness of local healthcare systems were recorded as means and standard deviations.

\section{Results}

\subsection{Practices of Using Local Health Centers Depending on the Characteristics of the Respond-} ents

The practices of using local health centers depending on the characteristics of the respondents are shown in Table 1. The proportion of using health centers in Gimcheon was found to be $39.1 \%$, and the number of times visiting health centers was found to be 3.92. Among the health center visitors, the proportion of females was $30.3 \%$, which was much higher than the proportion of males $(8.8 \%)$. However, males tended to use health centers more frequently (4.21 times) than females (3.76 times) $(p<0.001)$. Among the age groups, the ratio of 50 59-year-old respondents who visited health centers was the highest $(9 \%)$, while the ratio of those in their 20 s was the lowest $(2 \%)$. The number of respondents using health centers was the highest for those in their 50s (4.25 times) and the lowest for those in their 20s (3.37) $(p<0.001)$. There were differences in using health centers. Housewives used them the most $(11.0 \%)$, followed by farmers $(10.3 \%)$, service providers $(6.4 \%)$, office workers $(5.1 \%)$, technicians $(4.6 \%)$, and others $1.7 \%(p<0.001)$. Those who lived within $30 \mathrm{~min}$ of travel time from health centers $(23.2 \%)$ visited them 4.34 times on average, and those who required more than $30 \mathrm{~min}$ to visit centers (15.9\%) used them 3.61 times on average $(p<0.001)$.

\subsection{Awareness Of, Use Of, and Satisfaction with Local Healthcare Projects}

The awareness of, use of, and satisfaction with local healthcare projects are illustrated in Table 2. The average proportion of those who were aware of local healthcare projects was $45.5 \%$, and that of those using projects was $8.3 \%$; their satisfaction score was 3.92 on a five-point Likert scale. The project that the highest proportion of respondents was aware of was vaccinations (84.5\%), followed by medical examinations $(67.5 \%)$, stop-smoking programs $(66.2 \%)$, diabetes care $(43.5 \%)$, and hypertension care $(42.3 \%)$. The project that was known by the smallest number of respondents was visiting healthcare $(28.9 \%)$. The project that was used by the largest proportion of people was vaccinations $(38.1 \%)$, followed by medical examinations $(20.3 \%)$, mother and child health $(5.9 \%)$, and stop-smoking programs $(5.6 \%)$. The proportions of those using centers for dementia care and infectious disease care were the lowest $(2.7 \%$ each). The project respondents expressed the highest satisfaction for stop-smoking programs (4.26 points), followed by vaccinations (4.14 points), visiting healthcare (4.13 points), and diabetes care (4.04). The score of medical examinations was the lowest (3.51 points). 
Table 1. Practices of using local health centers depending on the characteristics of the respondents.

\begin{tabular}{|c|c|c|c|c|c|}
\hline \multirow{2}{*}{ Characteristic } & \multirow{2}{*}{$n(\%)$} & \multicolumn{2}{|c|}{ Utilization } & \multicolumn{2}{|c|}{ Number of Use } \\
\hline & & Yes, $n(\%)$ & $p^{*}$ & Mean \pm SD & $p^{* *}$ \\
\hline Gender & & & $<0.001$ & & $<0.001$ \\
\hline Male & $146(35.7)$ & $36(8.8)$ & & $4.21 \pm 1.39$ & \\
\hline Female & $263(64.3)$ & $124(30.3)$ & & $3.76 \pm 1.58$ & \\
\hline Age (years) & & & $<0.001$ & & $<0.001$ \\
\hline 20 29 & $27(6.6)$ & $8(2.0)$ & & $3.37 \pm 1.77$ & \\
\hline $30 \sim 39$ & 79 (19.3) & $32(7.8)$ & & $3.75 \pm 1.66$ & \\
\hline $40 \sim 49$ & $58(14.2)$ & $25(6.1)$ & & $3.65 \pm 1.52$ & \\
\hline $50 \sim 59$ & $94(23.0)$ & $37(9.0)$ & & $4.25 \pm 1.38$ & \\
\hline $60 \sim 69$ & $71(17.4)$ & $30(7.3)$ & & $4.21 \pm 1.40$ & \\
\hline$\geq 70$ & $80(19.5)$ & $28(6.8)$ & & $3.93 \pm 1.62$ & \\
\hline Education & & & 0.465 & & 0.201 \\
\hline$\leq$ Primary & $74(18.1)$ & $28(6.8)$ & & $3.64 \pm 1.68$ & \\
\hline Middle & $60(14.7)$ & $19(4.6)$ & & $3.70 \pm 1.64$ & \\
\hline High & $119(29.1)$ & $51(12.5)$ & & $4.12 \pm 1.32$ & \\
\hline Collage & $54(13.2)$ & $20(4.9)$ & & $4.14 \pm 1.56$ & \\
\hline$\geq$ University & $102(24.9)$ & $42(10.3)$ & & $3.86 \pm 1.53$ & \\
\hline Occupation & & & $<0.001$ & & 0.003 \\
\hline Office worker & $64(15.6)$ & $21(5.1)$ & & $3.92 \pm 1.59$ & \\
\hline Service worker & $72(17.6)$ & $26(6.4)$ & & $4.17 \pm 1.38$ & \\
\hline Tech worker & 57 (13.9) & $19(4.6)$ & & $3.81 \pm 1.52$ & \\
\hline Agriculture & $94(23.0)$ & $42(10.3)$ & & $4.19 \pm 1.43$ & \\
\hline House wife & $89(21.8)$ & $45(11.0)$ & & $4.22 \pm 1.45$ & \\
\hline Others & $33(8.1)$ & $7(1.7)$ & & $3.58 \pm 1.72$ & \\
\hline Marital status & & & 0.370 & & 0.218 \\
\hline Single & 97 (23.7) & $34(8.3)$ & & $3.78 \pm 1.65$ & \\
\hline Married & $312(76.3)$ & $126(30.8)$ & & $4.13 \pm 1.47$ & \\
\hline Travel time & & & $<0.001$ & & $<0.001$ \\
\hline$<30 \mathrm{~min}$ & $198(48.4)$ & $95(23.2)$ & & $4.34 \pm 1.43$ & \\
\hline$\geq 30 \mathrm{~min}$ & $211(51.6)$ & $65(15.9)$ & & $3.61 \pm 1.77$ & \\
\hline Total & 409 (100) & $160(39.1)$ & & $3.92 \pm 1.55$ & \\
\hline
\end{tabular}

SD, standard deviation; ${ }^{*} p$-value obtained from a chi-square test; ${ }^{* *} p$-value obtained from a $t$-test or a one-way ANOVA. 
Table 2. Awareness of, use of, and satisfaction with local healthcare projects.

\begin{tabular}{lccc}
\hline \multicolumn{1}{c}{ Characteristic } & Awareness ${ }^{\text {a }}$ & Utilization ${ }^{\mathbf{a}}$ & Satisfaction $^{\mathbf{b}}$ \\
\hline Medical examinations & $276(67.5)$ & $83(20.3)$ & $3.51 \pm 1.35$ \\
\hline Vaccinations & $345(84.5)$ & $156(38.1)$ & $4.14 \pm 1.27$ \\
\hline Mother and child health & $152(37.2)$ & $24(5.9)$ & $3.95 \pm 0.91$ \\
\hline Hypertension care & $173(42.3)$ & $18(4.4)$ & $4.01 \pm 1.13$ \\
\hline Diabetes care & $178(43.5)$ & $20(4.9)$ & $4.04 \pm 1.05$ \\
\hline Dementia care & $137(33.5)$ & $11(2.7)$ & $3.92 \pm 1.24$ \\
\hline Mental illness care & $123(30.1)$ & $13(3.2)$ & $3.88 \pm 0.81$ \\
\hline Disabled person care & $165(40.3)$ & $14(3.4)$ & $4.01 \pm 1.15$ \\
\hline Infectious diseases care & $144(35.2)$ & $11(2.7)$ & $3.70 \pm 0.98$ \\
\hline Stop-smoking programs & $271(66.2)$ & $23(5.6)$ & $4.26 \pm 1.13$ \\
\hline Dental healthcare & $154(37.6)$ & $18(4.4)$ & $4.02 \pm 1.16$ \\
\hline Visiting healthcare & $118(28.9)$ & $15(3.7)$ & $4.13 \pm 1.07$ \\
\hline Average & $186(45.5)$ & $34(8.3)$ & $3.92 \pm 1.06$ \\
\hline Values: Presin
\end{tabular}

Values: Presented as number (\%) or mean \pm standard deviation. Results from: ${ }^{\text {a }}$ The frequency analysis; ${ }^{b}$ the descriptive analysis.

\subsection{Analysis of the Variables Affecting the Use of Local Healthcare Projects}

The author of this study performed multiple regression analysis using gender, age, education level, job, marital status, and travel time as the independent variables and the use and frequency of using local health centers as the dependent variables. The findings are shown in Table 3. The explanatory power of the model regarding the use of local health centers was $13.1 \%$. Among the independent variables, travel time $(\beta=0.235)$ was the most powerful variable, followed by gender $(\beta=0.154)$, age $(\beta=0.140)$, job $(\beta=$ $0.1020)$, education level $(\beta=0.086)$, and marital status $(\beta=0.82)$. The explanatory power of the model regarding the frequency of using local health centers was $11.5 \%$. The most powerful independent variable was travel time $(\beta=0.187)$, followed by age $(\beta=0.124)$, educational level $(\beta=0.101)$, and gender $(\beta=0.082)$.

Table 3. Analysis of the variables affecting the use of local healthcare projects.

\begin{tabular}{lcccccccccc}
\hline Independent & \multicolumn{4}{c}{ Use } & \multicolumn{4}{c}{ Number of Use } \\
\cline { 2 - 13 } \multicolumn{1}{l}{ Variable } & $\mathbf{B}$ & SE & $\boldsymbol{\beta}$ & $\boldsymbol{t}$ & $\boldsymbol{p}$ & $\mathbf{B}$ & SE & $\boldsymbol{\beta}$ & $\boldsymbol{t}$ & $\boldsymbol{p}$ \\
\hline Travel time & 0.506 & 0.084 & 0.235 & 6.098 & $<0.001$ & 0.339 & 0.072 & 0.187 & 4.728 & $<0.001$ \\
\hline Gender & 0.656 & 0.162 & 0.154 & 3.876 & $<0.001$ & 0.284 & 0.140 & 0.082 & 2.025 & 0.053 \\
\hline Age & 0.018 & 0.005 & 0.140 & 3.614 & $<0.001$ & 0.011 & 0.014 & 0.124 & 2.755 & $<0.001$ \\
\hline Occupation & 0.079 & 0.031 & 0.102 & 2.549 & 0.012 & - & - & - & - & - \\
\hline Education & 0.280 & 0.124 & 0.086 & 2.241 & 0.025 & 0.262 & 0.115 & 0.101 & 2.518 & 0.013 \\
\hline Marital status & 0.163 & 0.097 & 0.082 & 2.185 & 0.034 & - & - & - & - & - \\
\hline
\end{tabular}

SE, standard error. Use: $F=17.683, R^{2}=0.131$, adjusted $R^{2}=0.122$. Number of use: $F=10.471, R^{2}=$ 0.115 , adjusted $R^{2}=0.110$.

\subsection{Local Healthcare Projects Needed in the With-COVID-19 Age}

The projects regarded by respondents as needing to be strengthened or implemented in the with-COVID-19 age are shown in Table 4. Vaccinations received the highest score (4.15), followed by infectious disease care (4.12), visiting healthcare (4.07), medical examinations (4.02), disabled person care (3.98), mother and child health (3.96), hypertension care (3.93), diabetes care (3.91), mental disease care (3.84), dementia care (3.83), stop-smoking programs (3.73), and dental healthcare (3.70). 
Table 4. Local healthcare projects needed in the with-COVID-19 age.

\begin{tabular}{|c|c|c|c|c|c|c|}
\hline Characteristic & $\begin{array}{c}\text { Very Nec- } \\
\text { essary }\end{array}$ & Necessary & Usually & $\begin{array}{c}\text { Unneces- } \\
\text { sary }\end{array}$ & $\begin{array}{c}\text { Very Unnec- } \\
\text { essary }\end{array}$ & $\begin{array}{c}\text { Mean } \pm \\
\text { SD }\end{array}$ \\
\hline $\begin{array}{l}\text { Medical examina- } \\
\text { tions }\end{array}$ & $157(38.4)$ & $123(30.1)$ & $115(28.1)$ & $9(2.2)$ & $5(1.2)$ & $4.02 \pm 0.96$ \\
\hline Vaccinations & $181(44.2)$ & $120(29.3)$ & $98(24.0)$ & $8(2.0)$ & $2(0.5)$ & $4.15 \pm 1.05$ \\
\hline $\begin{array}{l}\text { Mother and child } \\
\text { health }\end{array}$ & $150(36.7)$ & $116(28.4)$ & $125(30.6)$ & $12(2.9)$ & $6(1.5)$ & $3.96 \pm 1.17$ \\
\hline Hypertension care & $142(34.7)$ & $121(29.6)$ & $128(31.3)$ & $13(3.2)$ & $5(1.2)$ & $3.93 \pm 0.94$ \\
\hline Diabetes care & $135(33.1)$ & $120(29.3)$ & 138 (33.7) & $13(3.2)$ & $3(0.7)$ & $3.91 \pm 1.03$ \\
\hline Dementia care & $125(30.6)$ & $118(28.9)$ & $145(35.4)$ & $14(3.4)$ & $7(1.7)$ & $3.83 \pm 1.15$ \\
\hline Mental illness care & $132(32.3)$ & $110(26.9)$ & $144(35.2)$ & $17(4.1)$ & $6(1.5)$ & $3.84 \pm 1.14$ \\
\hline $\begin{array}{l}\text { Disabled person } \\
\text { care }\end{array}$ & $155(37.9)$ & $115(28.1)$ & $122(29.8)$ & $11(2.7)$ & $6(1.5)$ & $3.98 \pm 1.06$ \\
\hline $\begin{array}{l}\text { Infectious diseases } \\
\text { care }\end{array}$ & $177(43.3)$ & 118 (28.9) & $103(25.2)$ & $9(2.2)$ & $2(0.5)$ & $4.12 \pm 1.15$ \\
\hline $\begin{array}{l}\text { Stop-smoking pro- } \\
\text { grams }\end{array}$ & $117(28.6)$ & $111(27.1)$ & $145(35.5)$ & $25(6.1)$ & $11(2.7)$ & $3.73 \pm 1.02$ \\
\hline Dental healthcare & $114(27.9)$ & $109(26.7)$ & 147 (35.9) & $28(6.8)$ & $11(2.7)$ & $3.70 \pm 0.98$ \\
\hline Visiting healthcare & $166(40.6)$ & $121(29.6)$ & $109(26.7)$ & $10(2.4)$ & $3(0.7)$ & $4.07 \pm 0.81$ \\
\hline
\end{tabular}

\section{Discussion}

It has been a long time since the COVID-19 pandemic started. However, unlike other corona-type viruses such as SARS and MERS, COVID-19 has continuously spread. With the development of vaccines against COVID-19, people expected that the virus would end [3,7]. However, the genetic variation of the spike protein on the surface of the virus caused breakthrough infections among those who had already become vaccinated, again leading to a wide spread of the virus $[22,23]$. Now, it is time to prepare for an age in which we coexist with COVID-19.

Traditionally, the ultimate goal of coping with an infectious disease has been the end of the disease. For instance, in the case of the COVID-19 pandemic, the initial response was intended to stop the appearance of confirmed cases. Though many countries have made efforts to terminate the virus, many seem to have accepted the reality that it may be impossible to do so. As such, we are now talking about living with the virus. To live with COVID-19, we must adjust ourselves to it. To adjust ourselves to and coexist with the virus, we need to establish good healthcare systems [24,25].

Healthcare systems can be said to be the immunity systems that humans have established to cope with infectious diseases such as COVID-19. As each individual has a unique immune system, each region has established a unique healthcare system depending on its economic, cultural, and political characteristics. Consequently, each region has to reinforce its healthcare system to deal with COVID-19. To realize this purpose, the author of this study wanted to help their region to better prepare its healthcare system by analyzing the awareness of local residents.

This study revealed that the ratio of visiting health centers and health center branches in Gimcheon was 39.1\% and that, on average, people visit centers or branches 3.92 times a year. The ratio of visiting health centers and health center branches in Gimcheon $(39.1 \%)$ was found to be higher than the average ratio of visiting such facilities among residents of medium- and small-sized cities in Korea. The frequency of visiting such facilities in the city (3.92 times) was similar to frequency of less than five times found in other cities [26,27]. The proportion of respondents who were aware of local healthcare projects was $45.5 \%$, that of using the projects was $8.3 \%$, and their average five-point Likert scale satisfaction score was 3.92. The project that the highest proportion 
of respondents was aware of was vaccinations (84.5\%). The project respondents used the most frequently was vaccinations $(38.1 \%)$, and the project that they were most satisfied with was stop-smoking programs (4.26), followed by vaccinations (4.14).

The survey was performed in March and April of 2021, when full-scale vaccination against COVID-19 started. Thus, the proportions of awareness and the use of vaccinations may have been higher than in normal times. Satisfaction with vaccinations was also found to be high. Currently, it is impossible to end the spread of COVID-19 by vaccination. However, in the with-COVID-19 age, vaccinations could dramatically reduce the morbidity and death rates of patients [28]. Therefore, local healthcare systems need to attempt to reduce morbidity and death rates by vaccinating local residents and forming herd immunity.

It was also found that $70.9 \%$ of the residents lived within $30 \mathrm{~min}$ of travel time from health centers or health center branches; $23.2 \%$ of those who lived within 30 min of travel time from such facilities used them 4.34 times a year, while $15.9 \%$ of those who lived outside of 30 min of travel time used them 3.61 times a year, proving that travel time affects the use of such facilities. Regression equations employing the use and frequency of use of health centers showed that the most influential variable was travel time. Consequently, to increase the use of health centers and satisfaction with healthcare projects, it is necessary to inform residents of the locations of health centers and healthcare projects. However, in preparation for the with-COVID-19 age, it is necessary to provide residents with untact remote treatment to allow for access to healthcare regardless of travel time. In particular, when dealing with highly infectious diseases such as COVID-19, treatment and prescription should be made with minimal human-human contact. Through untact remote treatment, some of the unsatisfied medical problems in hard-to-access areas can be solved.

Finally, among the healthcare projects in the with-COVID-19 age that need to be revised or implemented with full force, vaccinations (4.15) and infectious disease management (4.12) were ranked as most important by the respondents, which shows that vaccinations and infectious disease management conducted via the expansion of healthcare facilities and personnel is important. It is difficult to predict the potential scale of the spread and seriousness of infectious diseases such as COVID-19. Therefore, there are limits for private medical institutions to deal with such an infectious disease. Thus, public medical facilities at the national and local government levels should help. However, currently in Korea, the public health infrastructure needs improvement. Though the number of hospital beds per 1000 people is not small, a number of COVID-19 patients have been unable to secure hospital beds; when convicted cases of COVID-19 rose abruptly, some of these patients died under self-quarantine at home $[29,30]$. Consequently, to properly respond to infectious diseases such as COVID-19, it is necessary for the central government to establish infectious disease-specializing hospitals and for local governments to establish local infectious disease-specializing medical centers.

In the with-COVID-19 age, local healthcare systems will face new changes. A new approach is needed for local healthcare, which has been neglected. Untact medical environments demand changes in medical service supply and the use of healthcare services. In addition, the improvements and role enlargements of local healthcare systems to respond to public health crises will become important issues in the with-COVID-19 age. This study, based on cross-sectional analysis, cannot suggest clear causal paths among variables of local public health systems. However, through its analysis of the awareness of local residents regarding local public health systems, this study can suggest some ideas about revising local public health systems in Korea. 


\section{Conclusions}

By examining what public health projects local residents need in the with-COVID-19 age, the author of this study aimed to provide help to local public health systems. The findings of this analysis suggest the following ideas regarding local public health projects in the with-COVID-19 age. First, local public health authorities should attempt to form herd immunity, as well as lower morbidity and death rates for patients, by activating vaccinations. Second, these authorities should try to block the spread of infectious diseases and solve unsatisfied medical problems in inaccessibly remote areas through untact remote treatment. Third, the central government should establish infectious disease-specializing hospitals, and local governments should establish infectious disease management systems based on such national hospitals.

Acknowledgments: This research was supported by Gimcheon University research grants in 2021.

\section{References}

1. Yang, S.H. A Study on the Evaluation Standards for the Government Response to COVID-19: By Comparing International Health Regulations(2005) with Analyses of MERS-CoV. The Journal of Humanities and Social science 2020, 11(2), 1613-1626.

2. Person, B.; Sy, F.; Holton, K.; Govert, B.; Liang, A. Fear and stigma: The epidemic within the SARS outbreak. Emerging Infectious Diseases 2004, 10(2), 358-363.

3. Koff, W.C.; Williams, M.A. Covid-19 and immunity in aging populations - a new research agenda. New England Journal of Medicine 2020, 383(9), 804-805.

4. MEDICAL Observer. Corona 19 is a complete end, group immunity is difficult... to be indigenous: https://www.monews.co.kr/news/articleView.html?idxno=303713 (accessed on 18 July 2021).

5. Future and Science. Scientists "Corona 19 will remain endemic even after the pandemic ends": https://www.hani.co.kr/arti/science/science_general/983458.html (accessed on 18 July 2021).

6. Benzell, S.G.; Collis, A.; Nicolaides, C. Rationing social contact during the COVID-19 pandemic: Transmission risk and social benefits of US locations. Proceedings of the National Academy of Sciences 2020, 117(26), 14642-14644.

7. Yun, G.J. Changes and Tasks in Korea's Healthcare System in Times of the Covid-19 Pandemic. Health and welfare policy forum 2020, 290, 34-49.

8. Lee, M.S. Overcoming the COVID-19 Epidemics with Communities in Korea. Journal of agricultural medicine and community health 2020, 45(1), $41-46$.

9. Kim, N.S. Health Research in Times of Living with Covid-19. Health and Social Welfare Review 2020, 40(3), 5-9.

10. Kim, M.J.; Lee, D.H. Healthcare Resources Management for Responding to the COVID-19 Pandemic: A Comparative and Institutional Study on the Case of ROK and Japan. Health and Social Welfare Review 2021, 41(2), 27-43.

11. Issac, A.; Stephen, S.; Jacob, J.; Vr, V.; Radhakrishnan, R.V.; Krishnan, N.; et al. The Pandemic League of COVID-19: Korea Versus the United States, With Lessons for the Entire World. J Prev Med Public Health 2020, 53(4), 228-232.

12. Shim, M.S.; Lee, M.S.; Oh, N.R.; Kang, K.H. A Study on Duty Awareness of Public Health-Center Workers. Journal of the Korea Convergence Society 2010, 1(1), 83-91.

13. Oh, E.H. Recognition and Utilization of Maternal and Child Health Services of Public Health Center. Health Service Management Review 2017, 11(3), 27-33.

14. Malcarney, M.B.; Pittman, P.; Quigley, L.; Horton, K.; Seiler, N. The Changing Roles of Community Health Workers. Health Services Research 2017, 52(1), 360-382.

15. Kim, J.H. The Analysis of Priority Setting in Community Health Planning in Korea and its Implications. Journal of the Korea Contents Association 2015, 15(1), 264-275.

16. Ministry of Health and Welfare. Local Health https://www.lawnb.com/Info/ContentView?sid=L000000236 (accessed on 20 July 2021).

17. Kim, H.S.; Park, Y.H. Related Factors on Health Service Utilization and Satisfaction of Health Center Clients: Using '2010 Community Health Survey. The Korean Journal of Health Service Management 2013, 7(3), 95-109. 
18. Corburn, J. Confronting the Challenges in Reconnecting Urban Planning and Public Health. American Journal of Public Health 2004, 94(4), 541-546.

19. Macintyre, S.; Ellaway, A.; Cummins, S. Place effects on health: how can we conceptualise, operationalise and measure them?. Social Science \& Medicine 2002, 55(1), 125-139.

20. Han, G.S. Utilization and Factors Associated in Public Health Centers in Incheon Metropolitan City. The Korean Society of Dental Hygiene Science 2015, 15(6), 728-735.

21. Jo, H.S.; Hwang, M.S.; Lee, H.J. Market segmentation of health information use on the Internet in Korea. International Journal of Medical Informatics 2010, 79(10), 707-715.

22. Medical News. Corona 19 Delta Variations Continue to Global Diffusion: https://www.bosa.co.kr/news/articleView.html?idxno=2154129 (accessed on 28 July 2021).

23. Ottersen, O.P.; Engebretsen, E. COVID-19 puts the Sustainable Development Goals center stage. Nature Medicine 2020, 26, 1672-1673.

24. Alwan, N.A.; Bhopal, R.; Burgess, R.A.; Colburn, T.; Cuevas, L.E.; Smith, G.D.; et al. Evidence informing the UK's COVID-19 public health response must be transparent. The Lancet 2020, 395(10229), 1036-1037.

25. Ravichandran, K.; Anbazhagan, S.; Singh, S.V.; Agri, H.; Rupner, R.N.; Rajendran, V.K.O.; et al. Global Status of COVID-19 Diagnosis: An Overview. J Pure Appl Microbiol 2020, 14(suppl 1), 879-892.

26. Park, Y.J.; Park, H.H.; Ryu, S.Y. Factors Associated with Active Participation in Health Promotion Programs at a Public Health Center. Journal of Agricultural Medicine and Community Health 2010, 35(3), $287-300$.

27. Nam, C.W.; Lee, M.S. Evaluating the Efficiency of Public Health Center - Focused on Public Health Centers in Gyeongbuk. Journal of the Korean Urban Management Association 2011, 24(1), 65-87.

28. Medical News. condition for going to the Weed Corona: https://www.bosa.co.kr/news/articleView.html?idxno=2156205 (accessed on 14 August 2021).

29. Oh, Y.H. Problem with and Policy Agenda for Public Health Services in Korea. Health and Welfare Forum 2013, 200, 62-82.

30. Hankyoreh News. 13th fatality in Daegu...he's dead in a private room: https://www.hani.co.kr/arti/area/yeongnam/930076.html\#csidx27156e40fa11286937427a68eada438 (accessed on 14 August 2021). 